\title{
PREVALENCE OF CROSS BITE AMONG THE ORTHODONTIC PATIENTS IN BANGABANDHU SHEIKH MUJIB MEDICAL UNIVERSITY
}

\author{
NAZNIN SULTANA ${ }^{1}$, GAZI SHAMIM HASSAN, ${ }^{2}$ DIGAMBER JHA ${ }^{3}$, TOWHIDA NASHRIN ${ }^{4}$ LUTFUN NAHAR $^{5}$, \\ MIR ABU NAIM ${ }^{6}$
}

\begin{abstract}
Crossbite is one of the most prevalent malocclusion, posterior crossbite occurs in $8 \%$ to $22 \%$ of orthodontic cases and anterior crossbite has been seen in Class III cases, which accounts for 3.4\% of orthodontic cases. The etiology of posterior crossbite can include any combination of dental, skeletal, and neuro muscular functional components, but the most frequent cause is reduction in width of the maxillary dental arch.

Patients/cases seeking comprehensive orthodontic treatment in between 5 to 35 years were diagnosed for crossbite with diagnostic model and care record file.

Out of 300 cases 163(54.3\%) had crossbite, 90(30\%) had anterior crossbite and 109(36.3\%) had posterior cross bite. Among posterior crossbite 60(20\%) had unilateral and 49(16.3\%) had bilateral crossbite. Posterior crossbite was more prevalent than anterior crossbite. Cases with Class I molar relation showed more crossbite. Crossbite was more prevalent in cases with congenitally missing teeth.
\end{abstract}

Received: 27 February 2014

Accepted: 18 December 2014

\section{Introduction}

Posterior cross bite is one of the most prevalent malocclusions in the primary and early mixed dentition and is reported to occur in $8 \%$ to $22 \%$ of the cases. ${ }^{1-3}$ It is defined as any abnormal buccallingual relation between opposing molars, premolars, or both in centric occlusion. The most common form is a unilateral presentation with a functional shift of the mandible toward the crossbite side, which occurs in $80 \%$ to $97 \%$ of cases. ${ }^{3}$

The etiology of posterior cross bite can include any combination of dental, skeletal, and neuro muscular functional components, but the most frequent cause is reduction in width of the maxillary dental arch. Such reduction can be induced by finger sucking, ${ }^{4-6}$ certain swallowing habits, ${ }^{5}$ or obstruction of the upper airways caused by adenoid tissues or nasal allergies. ${ }^{6,7}$ Other etiologies of cross bites include prolonged retention or premature loss of deciduous teeth, crowding, palatal cleft, genetic control, arch deficiencies, abnormalities in tooth anatomy or eruption sequence, oral digit habits, oral respiration during critical growth periods, and malfunctioning temporomandibular joints. ${ }^{8}$

In a study by Jalber Almeida dos Santos et al in Brazil it was observed that $28.1 \%$ of school children has cross bite. Highest frequency was seen among 13 year old(39.3\%), followed by 14 year old(32.0\%). Regarding the type of cross bite $45.9 \%$ had unilateral cross bite, while $34.4 \%$ had anterior crossbite. ${ }^{9}$ In another study by Cuc Albinita and Cuc $\mathrm{O}$ it was observed that the frequency of cross bite is the highest between 10-13 years old $-5.80 \%$, in comparison to the age group of 6-9 years old $-4.54 \%$ in Brail. ${ }^{10}$

Yet no significant studies have been done on the prevalence of cross bite in Bangladeshi population. This study is an attempt to find out the prevalence of cross bite in Bangladeshi population and its variation in age and gender. This study would be helpful in the diagnosis and correction of cross bite in Bangladeshi population.

1. BDS, FCPS(Orthodontics and Dentofacial Orthopaedics)

2. Chairman, Dept. of Orthodontics, BSMMU

3. MS(Phase B), Dept. of Orthodontics, BSMMU

4. BDS, FCPS(Orthodontics and Dentofacial Orthopaedics)

5. FCPS(Part II trainee), Dept. of Orthodontics, BSMMU

6. FCPS(Part II trainee), Dept. of Orthodontics, BSMMU

Address of Correspondence: Dr.Naznin Sultana, BDS, FCPS (Orthodontics and Dentofacial Orthopaedics)

Bangladesh J Medicine 2015; $26: 9-12$ 


\section{Material and methods}

Patients between the age of 5 years and 35 years seeking orthodontic treatment were included in the study. Patients with incomplete clinical record and unwilling to participate in the study were excluded. Pre developed data sheet was used to record the findings. All the data were collected by same person.

Descriptive statistics was performed for the study variables. The prevalence of cross bite among male and female was determined. Prevalence of Cross bite among people with Cleft lip and palate, Adenoid, Mouth breathing, Thumb sucking, different Molar Relation, Congenitally missing teeth, Anomaly in Shape size, Narrow upper arch, Occlusal prematurity, Delayed eruption of teeth, Traumatic tooth loss and Premature loss of teeth was calculated. SPSS version 17 for Windows was used for data analysis.

\section{Result}

The sample consisted of 300 cases attending Outpatient department of Orthodontics in BSMMU among which 99 were male and 201 were female. The age range was from 7 years to 35 years with mean age of 18.33 years. Out of 300 cases $163(54.3 \%)$ had cross bite, $90(30 \%)$ had anterior cross bite and 109(36.3\%) had posterior cross bite. Among posterior cross bite $60(20 \%)$ had unilateral and $49(16.3 \%)$ had bilateral cross bite.

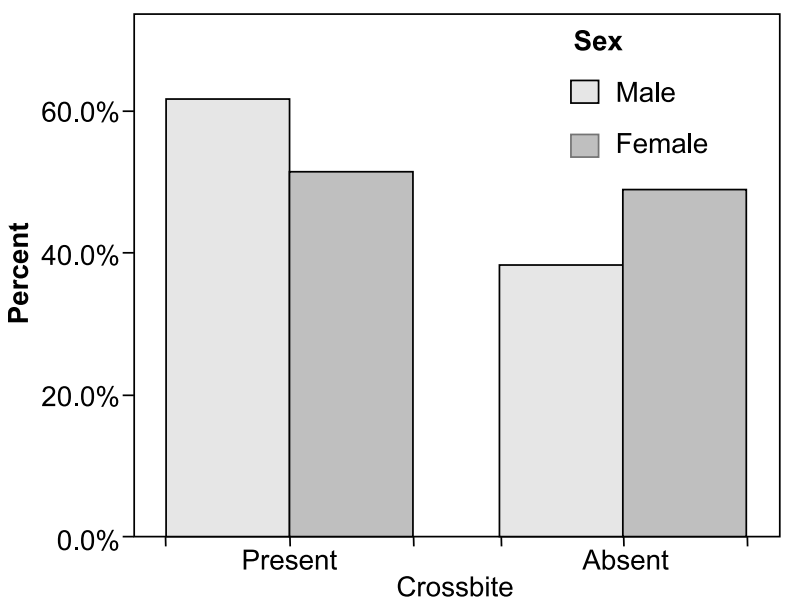

Fig.-1: Percentage of male and female with cross bite

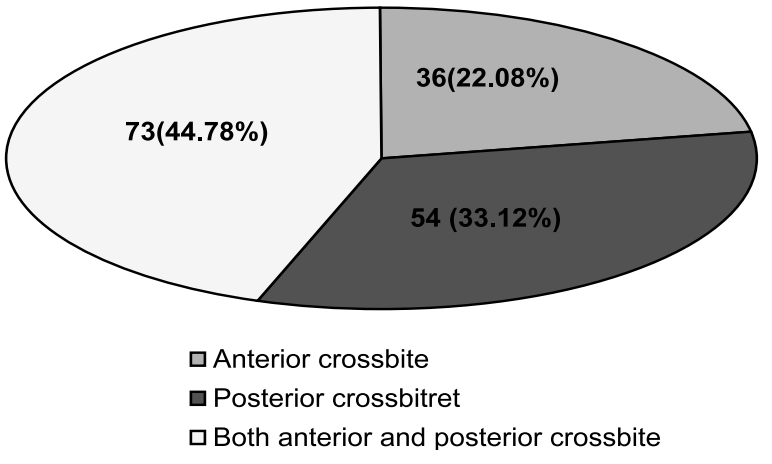

Fig.-2: Percentage anterior, posterior and both cross bite

Table I

Prevalence of cross bite among male and female

\begin{tabular}{|c|c|c|c|c|c|c|c|}
\hline & $\begin{array}{l}\text { Male } \\
\mathrm{N}=60\end{array}$ & $\begin{array}{l}\% \text { among } \\
\text { male with } \\
\text { cross bite }\end{array}$ & $\begin{array}{l}\text { Female } \\
\mathrm{N}=103\end{array}$ & $\begin{array}{c}\% \text { among } \\
\text { female with } \\
\text { cross bite }\end{array}$ & $\begin{array}{c}\text { Total } \\
\mathrm{N}=163\end{array}$ & $\begin{array}{l}\% \text { of total } \\
\text { cross bite }\end{array}$ & $\begin{array}{c}\text { Chi } \\
\text { square } \\
\text { test }\end{array}$ \\
\hline Cross bite & 21 & 35.00 & 33 & 32.00 & 54 & 33.12 & NS \\
\hline Both anterior and posterior & 15 & 25.00 & 21 & 20.38 & 36 & 22.08 & NS \\
\hline Posterior Cross bite & 24 & 40.00 & 49 & 47.57 & 73 & 44.78 & NS \\
\hline Unilateral Posterior Cross bite & 22 & 36.67 & 28 & 27.18 & 50 & 30.67 & NS \\
\hline Bilateral Posterior Cross bite & 17 & 28.33 & 32 & 31.06 & 49 & 30.00 & NS \\
\hline
\end{tabular}

Table II

Prevalence of cross bite in different molar relation

\begin{tabular}{lcccc}
\hline & Frequency & Percent & Cross bite & Cross bite percentage \\
\hline Class I & 189 & 63.0 & 99 & 60.73 \\
Class II & 68 & 22.7 & 30 & 18.40 \\
Class III & 28 & 9.3 & 24 & 14.72 \\
Class II sub div & 11 & 3.7 & 7 & 4.29 \\
Class II and Class III & 1 & 0.3 & 1 & 0.61 \\
missing molars & 2 & 0.7 & 1 & 0.61 \\
Class I and Class III & 1 & 0.3 & 1 & 0.61 \\
\hline Total & 300 & 100.0 & 163 & 100 \\
\hline
\end{tabular}


Table III

Prevalence of cross bite in different conditions

\begin{tabular}{lcccc}
\hline & Frequency & Percent & Cross bite & \% of total cross bite \\
\hline Cleft lip and palate & 8 & 2.7 & 8 & 4.90 \\
Family history & 10 & 3.3 & 5 & 3.06 \\
Mouth breathing & 2 & .7 & 2 & 1.22 \\
Thumb sucking & 4 & 1.3 & 3 & 1.84 \\
Retained deciduous & 13 & 4.3 & 8 & 4.90 \\
Missing teeth & 39 & 13.0 & 21 & 12.88 \\
Shape size anomaly & 6 & 2.0 & 4 & 2.45 \\
Narrow arch & 15 & 5.0 & 10 & 6.13 \\
Occlusal prematurity & 12 & 4.0 & 9 & 5.52 \\
Delayed eruption & 8 & 2.7 & 7 & 4.29 \\
Premature loss & 6 & 2.0 & 5 & 3.06 \\
\hline Total & 123 & 41 & 82 & 50.30 \\
\hline
\end{tabular}

Posterior cross bite was more prevalent than anterior cross bite. Cases with Class I molar relation showed more cross bite. Cross bite was more prevalent in cases with congenitally missing teeth.

\section{Discussion}

This study consisted of 300 cases attending the outpatient department of Orthodontic in BSMMU, out of which 201 were female and 99 were male. This clearly indicates the orthodontic awareness and concern in females than males. This is similar to the findings from other studies. ${ }^{10,11}$

Out of 300 cases $163(54.3 \%)$ had cross bite, most of the studies have shown it to be between 8 and 22 percent. ${ }^{1-3}$ The higher percentage of cross bite in this study might be because it was conducted among patients seeking orthodontic treatment and not the normal population and single tooth cross bite was also included in this study.

Distribution of cross bite among male and female Out of 54 anterior cross bite 21 was seen in male and 33 in female. $35 \%$ of cross bite in male was anterior cross bite and 32 percent of cross bite in female was anterior cross bite. 33.12 percent of total cross bite was anterior cross bite. 47 percent of female had posterior cross bite and 40 percent of male had posterior cross bite. 22 percent of cases had both anterior and posterior cross bite. This concludes that females had more cross bite than males. This is in accordance with the study by Sakib Naeem et al. in Pakistani population. ${ }^{12}$

Crossbite, anterior crossbite, posterior crossbite, unilateral posterior crossbite and bilateral crossbite all were non significant among male and female. This concludes that the distribution of crossbite among male and female is similar. This is similar to the result of study among school children in Brazil, among 13 to 17 age group. ${ }^{10}$

Distribution of cross bite in different molar relations Out of total cases there were 2 cases with missing molar and 1 among them had cross bite, 1 case of one side class II and other side Class III molar relation and 1 case of one side class I and other side Class III both had cross bite present. Out of 11 class II sub division cases 7 had cross bite. Class I cases showed most number of cross bite. As Class I cases were more in the study the most frequency of cross bite was noted in Class I cases. Asymmetric molar relation could be a contributing factor for cross bite.

Prevalence of cross bite in different conditions There were 8 cases of cleft lip and palate and all of them had cross bite, It can be concluded that cleft lip and palate was a major contributor to cross bite. Other factors like thumb sucking, family history, mouth breathing, retained deciduous tooth, congenitally missing teeth, size and shape anomaly in teeth, narrow arch, occlusal prematurity and delayed eruption can have significant influence in the development of cross bite according to the findings of this study. This is in accordance to the findings of previous studies. ${ }^{4-8}$

\section{Limitations of the Present Study}

This is a descriptive study and the specific contribution of each factor in the development of cross bite is not specified. It was a study conducted 
in the hospital only and everyone coming with orthodontic problem was included in the study. This might not exactly represent the prevalence of cross bite in the population.

\section{References}

1. Kutin G, Hawes RR. Posterior cross-bites in the deciduous and mixed dentitions. Am J Orthod. 1969; 56:491-504.

2. Egermark-Eriksson I, Carlsson GE, Magnusson T, Thilander B. A longitudinal study on malocclusion in relation to signs and symptoms of craniomandibular disorders in children and adolescents. Eur J Orthod. 1990;12:399-407.

3. Annicele da Silva Andradea, Gustavo Hauber Gameiro, Moara DeRossi, Maria Beatriz Duarte Gavia. Posterior Crossbite and Functional Changes. Angle Orthod. 2008;79:380-386.

4. Thilander B, Wahlund S, Lennartsson B. The effect of early interceptive treatment in children with posterior crossbite. Eur J Orthod. 1984;6:25-34.

5. Melsen B, Stensgaard K, Pedersen J. Sucking habits and their influence on swallowing pattern and prevalence of malocclusion. Europ J Orthod. 1979; 1: 271-280.
6. Linder-Aronson S. Adenoids. Their effect on mode of breathing and nasal airflow and their relationship to characteristics of the facial skeleton and the dentition. Acta Otolaryngol.1970;265:1-132.

7. Hannuksela A, Vaananen A. Predisposing factors for malocclusion in 7-year-old children with special reference to atopic diseases. Am J Orthod Dentofacial Orthop. 1987;92: 299-303.

8. David Allen, Joe Rebellato, Rose Sheats,Ana M. ceron. Skeletal and Dental contributors to Posterior crossbite. Angle Orthod. 2003;72: 515-524.

9. Jalber Almeida dos Santos, Alessandro Leite Cavalcanti, Yeska Paola Costa Aguiar. Prevalance of anterior and posterior crossbite in 13-17 year old schoolchildren attending municipal public schools in the city of Campina Grande(PB). South Brazilian Dentistry Journal. 2010:7(3):261-267.

10. Cuc Albinita, Cuc O. Reverse Crossbite-Statistical Study In the Period of Mixed Dentition.

11. Hamdan AM. The relationship between patient ,parent and clinician perceived need and normative orthodontic treatment need. Eur. J. Orthod 2004; 26: $265-71$

12. Saqib Naeem, Saad asad, M waheed-ul-Hamid. Prevalence of crossbite in orthodontic patients. Pakistan Oral \& Dental Journal. 2009; 20(2): 279-280. 